Canadian Oncology

Nursing Journal

Revue canadienne

de soins infirmiers

en oncologie

Volume 31, Issue 3 • Summer 2021

elSSN: 2368-8076 


\title{
The concept of coping in male spouses of Iranian women with breast cancer: A qualitative study using a phenomenological approach
}

\author{
by Marzieh Jahani Sayad Noveiri, Farshid Shamsaei, Masoud Khodaveisi, Zohreh Vanaki, Lily Tapak
}

\begin{abstract}
Introduction: Breast cancer is a multidimensional crisis that affects not just the patient, but the spouse and other family members. Coping with this phenomenon, as one of the important challenges for the families and spouses, requires investigation. Understanding more about how spouses of women with breast cancer cope with this crisis could lead to better performance of spouses in front of their wives and raise their wives' quality of life.
\end{abstract}

Purpose: The study was conducted to explore the concept of coping based on the lived experiences of spouses of women with breast cancer.

\section{AUTHOR NOTES}

Marzieh Jahani Sayad Noveiri, Student Research Committee, Hamadan University of Medical Sciences, Hamadan, Iran; jahanimzh@gmail.com

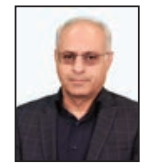

Farshid Shamsaei, Mother and Child Care Research Center, Hamadan University of Medical Sciences, Hamadan, Iran; (Correspondence) shamsaei68@yahoo.com

Masoud Khodaveisi, Chronic Diseases (Home Care) Research Center, Department of Community Health Nursing, Hamadan University of Medical Sciences, Hamadan, Iran; khodaveisi2000@yahoo.com

Zohreh Vanaki, Department of Nursing, Faculty of Medical Sciences, Tarbiat Modares University, Tehran, Iran; vanaki_z@ modares.ac.ir

Lily Tapak, Department of Biostatistics, School of Public Health, Modeling of Noncommunicable Diseases Research Center, Hamadan University of Medical Sciences, Hamadan, Iran; tapak@ umsha.ac.ir

Correspondence: Farshid Shamsaei, School of Nursing \& Midwifery, Hamadan University of Medical Sciences, Shahid Fahmideh Bulv., Hamadan 65178, Iran

Tel +98-81-38381941; Fax +98-81-38381942

Email: shamsaei68@yahoo.com

Acknowledgements: This article results from a $\mathrm{PhD}$ thesis supported by Hamadan University of Medical Sciences. The authors gratefully acknowledge the financial support provided by the vice chancellor of research and technology of Hamadan University of Medical Sciences.

Disclosure statement: No potential conflict of interest was reported by the authors.

Funding: This work was supported by Hamadan University of Medical Sciences, Hamadan, Iran (No. 9710256388)
Methods: This qualitative study was conducted with a phenomenological approach in Hamedan and Rasht cities in Iran in 2019. Participants included 20 spouses of women with breast cancer selected by a purposive sampling method. Data were collected through unstructured face-to-face interviews and analyzed using van Manen's six-stage phenomenological method.

Results: The lived experiences of participants showed that the phenomenon of coping in spouses of women with breast cancer included five themes: Emotional pain, Shouldering the burden of care, Striving for family life cohesion, Future in ambiguity, and Sense of loss of self concept. Understanding the concept of coping in the spouses of women with breast cancer in health strategies can help wives achieve effective adaptation and also help professionals take effective measures in the field of medical care for patients and their spouses.

Key words: breast cancer, coping, spouses, phenomenology

\section{INTRODUCTION}

D reast cancer is one of the most common types of canD cer in most countries, including in Iran. The incidence of breast cancer in Iran is estimated at 24.6 per 100,000 people (Abachizadeh et al., 2018). Breast cancer dramatically changes the lives of thousands of Iranian male spouses every year. Having breast cancer is regarded as a tragic and critical experience followed by such psychological responses as non-acceptance, denial, anger, stress and anxiety, hopelessness, uncertainty and despair for women and families, particularly spouses (Braun et al., 2007).

Breast cancer is regarded as the most common type of cancer in women and the second leading cancer of all cancers, such that more than 2.1 million new cases of breast cancer were registered at the World Cancer Statistics Center in 2018 (Bray et al., 2018; Momenimovahed \& Salehiniya, 2019). Next to lung cancer, breast cancer is the second leading cause of cancer-related mortality (15.4\%) in developed countries and the fifth in Iran with an estimated mortality rate of $14.2 \%$ (Nafissi et al., 2018). Despite advances in breast cancer diagnostic and treatment equipment in Iran, reports suggest that the prevalence of this disease is still increasing (Montazeri et al., 2008; Nasiri et al., 2016).

Breast cancer may have direct effects on the patients' spouses (Braun et al., 2007; Yusoff et al., 2012). For instance, distress is copiously observed among spouses of women with breast cancer. Some studies have reported that spouses experience even greater distress than the patients (Braun et al., 2007; 
Northouse et al., 2000). This could be due to the extra roles assumed by spouses as caregivers during treatment, and their own needs being neglected by relatives and medical personnel (Northouse et al., 2000; Soothill et al., 2003).

Researchers have investigated the issues relating to social support, marital relationships, and coping strategies in spouses of patients with breast cancer. The studies commonly point to the fact that breast cancer creates a new living environment for spouses, whose problems mostly circle around such issues as marital satisfaction, communication, and interpersonal support, which refer to the spouses' efforts to preserve the family environment (Dorval et al., 2005; Yusoff et al., 2012). Spouses need to cope with the circumstances in order to effectively support their life partner with breast cancer, keep stress away from the family environment, and effectively handle daily living affairs.

Coping is one of the fundamental challenges for spouses of women with breast cancer. Not only does the cancer affect their family life, but it also may impact their socioeconomic status, and create several problems for their marital relationships and roles (Gao et al., 2019; Lopes et al., 2018; Younes Barani et al., 2019). Coping means using cognitive-behavioural strategies to manage and control stress. It includes both problem-solving and emotion-based strategies. Problem-solving strategies are concerned with controlling the source of stress, while emotion-based strategies are efforts to control thoughts and emotions (Fink, 2016; Folkman \& Lazarus, 1988; Mehrabi et al., 2016). Coping happens differently in different people and at different times (Cebeci et al., 2012; Ghaffari et al., 2014). Spouses of patients with breast cancer use various coping strategies during self-control and self-management stages. One of the routine coping strategies among spouses is acceptance (Kershaw et al., 2004; Yeung et al., 2018), although it is applied differently in different people. The personal living experiences of people with breast cancer and their spouses are different from those who have not experienced this phenomenon. Coping experiences of spouses of women with breast cancer are also different from the women. Understanding the issue of coping will contribute to identifying opportunities and threats to the spouses' coping. It can also facilitate treatment of the patients and guide medical personnel in effectiveness of treating the patients.

Review of literature on coping of spouses of women with breast cancer identified some studies that had examined the needs of spouses of these women (Sajadian et al., 2015). However, no qualitative study could be found on coping experiences of Iranian spouses. Given the differences in Iranian society and the current cultural approach, beliefs, and values, using a qualitative approach appears to be the best method for examining coping experiences. With the above background in mind, the present qualitative study was conducted to obtain an in-depth understanding of the coping experiences of male spouses of women with breast cancer, in Iran.

\section{METHODS}

\section{Study design}

This qualitative study has an interpretive hermeneutic phenomenological approach. The approach is a qualitative methodology used to examine and understand the subjective, lived experience of individuals using an idiographic approach, in which detailed, individual cases are used to develop more general claims (Paley, 2018; Walker, 2007; Xiong et al., 2016). The aim of this methodology is to gain a deeper understanding of the human experience through description and interpretation. Through a hermeneutic approach of analysis, the tenets of Heidegger's phenomenological philosophy provided the opportunity to explore the concept of spouses coping with their wives' breast cancer in Iran.

\section{Participants and setting}

The participants included 20 spouses of women with breast cancer who were selected from hospitals in Hamedan and Rasht cities of Iran through purposive sampling. The inclusion criteria consisted of being a spouse caregiver, a definitive diagnosis of breast cancer in the women, and the spouse's mental and physical health. After obtaining their consent, the author conducted interviews with the spouses of women with breast cancer in the medical centres while their wives received treatment.

Twenty participants were recruited into this study. After the 18th interview, there were no new themes generated from the interviews. Therefore, it was deemed that the data collection had reached a saturation point. The research team continued data collection for two more interviews to ensure and confirm that there were no new themes emerging. Sample sizes in phenomenological studies are generally smaller and have varied from five to 30 participants (Smith, 2003).

\section{Data collection}

The researcher used in-depth interviews to gather information between December 2018 and August 2019. A private room within the hospital was used to conduct the unstructured interviews. The interviews started with an open-ended question such as "How has your spouse's breast cancer affected your life?" and continued with follow-up questions like "Explain more", and "Give an example". During the interview, the researcher always tried to encourage spouses to talk about their life experiences with the patients. The interviews lasted from 30 to 60 minutes, depending on the tolerance and cooperation of the spouse participants, and were digitally recorded. Observation notes were recorded by the interviewer to document participant expressions and body language. Based on the principles of phenomenology, researcher prejudgments were acknowledged and set aside for the purpose of truly understanding the experiences of the participants (Burkoski et al., 2019; Valle et al., 1989).

\section{Data analysis}

Data gathering and analyses were conducted simultaneously and, as the initial coding was done, it was decided to conduct some subsequent interviews. In the first two stages, the researcher tried to get a description of the lived experience 
of the male spouses of women with breast cancer. The data analysis process drew on van Manen's (1997) phenomenological methodology. The method involved listening to all recordings to familiarize the researcher and acquire a sense of participants' experiences. All digital recordings were then transcribed verbatim. Following transcription, thematic statements that contributed to participants' experiences and were of direct relevance to the phenomenon were extracted by the researcher using van Manen's (1997) highlighting approach. Meanings were derived from the statements, which were then organized into themes that were common across all participants (Burkoski et al., 2019). Themes were developed by the researcher and reviewed by the research team.

van Manen (2014) proposed six research activities as a methodological structure to guide hermeneutic phenomenological research. This structure was used in this study (van Manen, 2016). Involvement of the researcher with the research question at all times is one of the necessities of a study using interpretive phenomenology. The question, "What is the experience of adjustment in spouses of women with breast cancer?", constantly led the researcher to extract and interpret the themes at all stages of the study. Eventually, organized concepts led to a comprehensive description of the phenomenon.

The transcribed interviews were analyzed using van Manen's thematic analysis approach and according to activities 3-6 of the van Manen methodology. According to activity 3, each transcribed interview was considered as a whole and was read several times. A short description was written to summarize the entire interview in a few sentences or paragraphs (holistic thematic analysis). Then, the thematic statements were isolated using a selective approach. For this reason, the transcriptions were read constantly to recognize the statement(s) that seemed particularly essential and that could reveal the core concepts of men's coping experiences about women's breast cancer. These statements were highlighted. After extraction of the general themes, the similar themes were clustered.

Then, in line with activity 4 , we used the art of writing and rewriting to bring the studied phenomenon into written words. In activity 5 , the researchers tried to gain a deep understanding of the phenomenon. In activity 6 , using the hermeneutic method, the researchers repeatedly referred to the whole and the parts of the text to analyze how they were connected. Then, the extracted themes were altered and reconstructed according to their similarities. MAXQDA software was used for data management.

\section{Rigour of the study}

To ensure that rigour was achieved, Lincoln and Guba's (1985) criteria for creditability, transferability, dependability, and confirmability were addressed during the qualitative process. Credibility was addressed by recruiting diverse individuals, taking into consideration age, the difference in duration of conflict with experience (i.e., time since diagnosis), and different hospital units. To ensure transferability, in-depth descriptions of the spouses' lived experiences were sampled across two hospitals in different cities. Dependability was ensured by closely following data analysis procedures to obtain in-depth descriptions and transcription of spouses' lived experiences. Lastly, confirmability was achieved by ensuring that the research team's biases were not introduced (to maintain openness to the information provided by the participants) and by putting them aside throughout the research process.

\section{Ethical considerations}

The study was approved by the Ethics Committee of Hamadan University of Medical sciences (IR.UMSHA. REC.1397.606). An informed consent document provided to each participant explained the purpose of the research, detailed potential risks, and provided a confidentiality statement of how participant information would be securely handled.

\section{RESULTS}

\section{Demographic characteristics}

Participants included 20 spouses with a mean age of 51 years. The majority of the spouses had high school and higher education levels (45\%), lived in Guilan and Hamedan provinces, and were from different socioeconomic and ethnic backgrounds. All participants were male and from the Islamic religion. The time since diagnosis of their wives' cancer until conducting the study was less than a year in all cases. All participating men were healthy, lived with their wives, and were responsible for the care of their wives (see Table 1 ).

\section{Identified themes}

Analysis of participants' experiences led to the extraction of five themes, including emotional pain, shouldering the burden of care, striving for family life cohesion, future in ambiguity, and a sense of loss of self-concept. Based on these themes, the concept of coping was defined from the lived experiences of spouses of women with breast cancer. The concept included facing the vague future of the disease and finding relief from a sense of losing self-concept, which was achieved through striving for family life cohesion by bearing the emotional pain and shouldering the burden of patient care. Table 2 presents the themes extracted from the qualitative data. Examples of participants' experiences based on these themes are described below:

\section{Theme 1: Emotional pain}

This theme includes three subthemes: neglect and relief, spouse's unstable affections, and facing the patient's affections and emotions. Because of the patients' need for their spouses' attention and care at all times, most men feel neglected, and deprived of having fun, friends, and activities, which makes them feel lonely. Moreover, spouses are faced with constant changes in their own and their wives' feelings and emotions, and alternately experience hope and despair.

\section{Participant No. 10}

"I discontinued all my past chores, everything, even my green garden, because I could not attend to it. I have an orange orchard, which was infested with bugs because I couldn't do the spraying. I have no fun, all my intimate chats are with her." 
Table 1: The demographic details of the participants in the study of "The concept of coping in spouses of Iranian women with breast cancer"

\begin{tabular}{|c|c|c|c|c|c|}
\hline Participant No. & Age (years) & Education & Profession & Place of Residence & Ethnicity \\
\hline 2 & 54 & Ninth Grade & Electrician & Rasht & Gilac \\
\hline 3 & 50 & Fifth Grade & Farmer & Village & Gilac \\
\hline 4 & 47 & Associate Degree & Radiologist & Anzali & Gilac \\
\hline 6 & 55 & Illiterate & Laborer & Village & Gilac \\
\hline 7 & 49 & Primary School & Taxi driver & Rasht & Turk \\
\hline 8 & 50 & High School Diploma & House painter, theater, sport coach & Rasht & Fars \\
\hline 9 & 54 & Illiterate & Laborer (Plumber) & Village & Gilac \\
\hline 12 & 57 & Primary School & Construction worker & Village & Gilac \\
\hline 13 & 67 & Primary School & Farmer, orchardist & Village & Mazani \\
\hline 14 & 70 & Bachelor's Degree & Retired from the Air Force & Suburban Hamadan & Turk \\
\hline 15 & 32 & Bachelor's Degree & Curtain seller & Rasht & Gilac \\
\hline 16 & 44 & Bachelor's Degree & Employee & Hamadan & Fars \\
\hline 17 & 62 & High School Diploma & Retired & Hamadan & Fars \\
\hline 18 & 54 & Illiterate & Farmer & Suburban Hamadan & Turk \\
\hline
\end{tabular}

Table 2: Themes extracted from the qualitative data

\begin{tabular}{|l|l|}
\hline Main theme & Subtheme \\
\hline Emotional pain & $\begin{array}{l}\text { Neglect and relief, spouse's emotional } \\
\text { instability, } \\
\text { Facing the patient's emotions }\end{array}$ \\
\hline $\begin{array}{l}\text { Shouldering the } \\
\text { burden of care and } \\
\text { treatment }\end{array}$ & $\begin{array}{l}\text { The pressure of inadequate medical services, } \\
\text { spouse neglected by the medical team, } \\
\text { bearing the job and living cost pressures } \\
\text { Performing multiple roles }\end{array}$ \\
\hline $\begin{array}{l}\text { Striving for family } \\
\text { life cohesion }\end{array}$ & $\begin{array}{l}\text { Transition from denial to acceptance, } \\
\text { spouse's promising steps, spouse's coping } \\
\text { strategies, the effect on personal, family } \\
\text { and social interactions } \\
\text { Coldness of relationship }\end{array}$ \\
\hline Future in ambiguity & $\begin{array}{l}\text { Cancer as a vague event, hope and despair } \\
\text { conflict }\end{array}$ \\
\hline $\begin{array}{l}\text { A sense of losing } \\
\text { self-concept }\end{array}$ & $\begin{array}{l}\text { Spouse's physical torments, the effect of } \\
\text { spouse's spirit }\end{array}$ \\
\hline
\end{tabular}

Participant No. 4

"One is always worried whether one has done less than one could and something could happen. You have to do your best, but there are also these stresses. How far have you got and how successful have you been with all these efforts? Because there is always the problem whether something bad happens or not? You get a guilty conscience if you think you have done wrong somewhere."

Participant No. 1

"It was hard. MY wife had psychological problems, and since I had no one to help me with her treatment, I had to send her to her father's. She was in pain and needed rest. She is better now, but because of her medications, it was very hard earlier on, but it's better now. It was very intense at first, when she had psychological and mental problems."

Theme 2: Shouldering the burden of care and treatment

This theme consisted of four subthemes: pressure of inadequate medical services, medical team's neglect of the wife, work and livelihood pressures, and multiple roles.

In the face of the disease, the patient's spouse is faced with such problems as the lack of insurance organizations' support, procurement of medication being time-consuming, lack 
of trust in medications, exorbitant costs of medication, lack of access to proper medical and care services, inadequate access to information, and the lack of a single and efficient medical team. Solving each of these problems requires an all-out effort on the part of all medical echelons. In some cases, spouses complained about being ignored by the medical team; they stated that some decisions are made by the medical team in patriarchal manner and no attention is paid even to the basic needs of this group. Considering the traditional role of Iranian women (including the role of the mother, housekeeping, taking care of the family, and being focused on children and their happiness), after developing the disease and becoming passive in the family, all these roles are imposed on men in addition to their roles as husbands and fathers, and the spouse is the only player in this scene.

\section{Participant No. 4}

"It is not as if everything is available to a patient with a particular disease. For example, a medical team, or after chemotherapy, when we did not know what foods she should take, since there was no nutritionist in the team. You did not know what to do when a symptom appeared, because there was no one to provide you with the information. The team did not include a psychologist, nutritionist, or an oncologist. All these tormented us a lot."

Participant No. 7

"In treatment, the man is not considered. The hospital did not seek my consent when they wanted to operate.

Interviewer: "You mean you didn't know?"

"I did know, but they performed mastectomy without my consent."

Participant No. 11

"It's dreadful. You never have any form of financial support. There are families with nothing, and poor things have trouble coming up with small amounts. There is a problem with radiotherapy, and people want to come under the public system, but the device cannot meet the demand. On the other hand, the cost of private is huge and not acceptable by the insurance. Some people are only covered the social services and medical services and have to incur 10 to 15 million tomans."

Participant No. 6

"It wasn't like that before. Coming home from work, I used to go to bed. But I can't do that now and do most of her chores: wash her clothes, prepare her food and bed, take her to the doctors, and buy medications. I never did these things before, but now I have to."

Theme 3: Striving for family life cohesion

This theme includes five subthemes: transition from denial to acceptance; spouse's promising steps; spouses' coping strategies; affected personal, family, and social interactions; and coldness of relationship. All spouses had experienced the transitional periods from denial to acceptance of the new situation, and the period of transition through these stages had been different for each of them. Ultimately, spouses had used coping strategies to boost their own and the patient's morale. With all these strategies for coping with the problems, all participants considered their interpersonal, family, and social relationships affected by the disease and the circumstances created.

Participant No. 5

"To boost my wife's morale, we have been to four or five weddings, parties and birthday parties. We invited 10 people to our house last night for my daughter's birthday. We keep our spirit up."

Participant No. 14

"A psychoanalyst is also present in the sessions. We talk, which calms me down. I do calligraphy and painting as well."

Participant No. 4

"We were very much troubled after chemotherapy, we all were, since on the one hand, the family should not have a cold or a latent disease to protect the patient. Many family members are unable to be in touch and you remain alone with the disease and the patient."

Participant No. 10

"I can no longer have that kind of emotional and affective relationship, and I just put up with it. I try to have a relationship now and again. I don't let the gap widen any further, and I'd be the cause. The disease has already had its effect and damage."

\section{Theme 4: Future in ambiguity}

This theme consisted of two subthemes: cancer as a vague event, and hope and despair conflict. Most spouses talked about their constant fear of the word "cancer" before their wife developed the disease. After the diagnosis of cancer, they constantly feared losing the patient, and viewed the future sometimes in hope and sometimes in despair. They are not certain about the outcome of the disease or treatment.

Participant No. 4

"Trust in God is fair enough. These are only beautiful words, but not the reality in practice. It is not so simple to just leave everything to God's will with regard to someone with whom you have been living for years. One always worries that something bad could happen."

\section{Theme 5: A sense of losing one's self-concept}

This theme consists of two subthemes: the spouse's physical torments and the influence on the spouse's spirit. Most of the spouses of women with breast cancer reported they were always worried about the failure of treatment, and most of them complained about the burden and pressure of care which causes them many physical and psychological problems. The condition of the women's disease makes the spouse neglect himself and ignore his own needs.

Participant No. 12

"I've been sick myself and felt something on my face for a while. I used to wake up with a headache during the night, so I went to a doctor and had a brain scan, and he said that fortunately it was nothing and only a nervous pressure, and prescribed some medications. I kept everything to myself because I had no choice, as I could not talk to just anyone." 


\section{DISCUSSION}

Although many studies have been conducted to understand various aspects of the effect of breast cancer on spouses of afflicted women, few studies have attempted to clarify the lived experiences of spouses of these women in Iranian society. The present phenomenological study results showed that the concept of coping with the lived experience of being a spouse of a woman with breast cancer included future in ambiguity, sense of losing self-concept, spouses' striving for family life cohesion, bearing the emotional pain, and shouldering the burden of patient care. As the first supporter of the patient in the process of treatment and recovery, spouses can have a major role in helping the patients and the medical team. Understanding the concept of coping from the perspective of the male spouses of women with breast cancer and helping them to cope better with the situation has an important impact on the treatment and recovery of the patient.

One of the important study results was emotional pain. These spouses felt alone and were unhappy with the inadequate support by the medical personnel and their family. In addition, spouses bear the behavioural and emotional instability of their wives who suffer from the disease and become emotionally unstable themselves. Many studies have cited the experience of emotional instability and distress in both patients and their spouses (Charvoz et al., 2016; Duprez et al., 2017; Zimmermann, 2015). In a qualitative study conducted in Turkey, Çömez and Karayurt (2016) described the spouses' experiences of their wives' breast cancer as a crisis, as the spouses described their worries and fear of death. In another study, Hasson-Ohayon et al. (2010) emphasized the emotional despair, depression and anxiety of spouses and reported low support for the spouse from his family and friends during this process.

Shouldering the burden of care and treatment was another important finding of the present study of spouses. The spouses of women with breast cancer have several financial problems due to the treatment costs, as well as the inability to generate income. In many cases, loss of the patient's financial helping hand put them under much pressure. Several studies have acknowledged the financial pressures on spouses caused by breast cancer (Glajchen, 2004; Grunfeld et al., 2004; Weitzner et al., 1999). Other issues that concern Iranian spouses and caregivers include high treatment costs, lack of radiotherapy facilities in all centres, or breakdown or insufficiency of facilities needed for the large volume of referrals, accumulation of the best doctors in the capital, which results in the lack of access to specialists for all social strata, medication shortages and worries, lack of insurance organizations' support, and not assigning a single medical team to treat these patients. Given the definition of health equity, which is fair distribution of medical services among people and various societal classes (Zere et al., 2007), this problem is one of the biggest concerns of spouses of women with breast cancer in Iran.

Spouses of women with breast cancer strive for family life cohesion. The many problems created for these spouses, such as financial and medical problems, as well as their wives' physical and behavioural changes, and the adversity of pressure and burden on the family potentially disrupt the family cohesion and relationships. Dealing with this problem requires more effort on the part of the spouse as the family head. In the present study, all participating spouses acknowledged the need for striving for family life cohesion. In the spouses' view, their most important action was to preserve and boost the patients' morale, and all agreed that having a high morale is helpful in managing the disease. In their studies, Neris and Anjos (2014) and Zahlis and Lewis (2010) cited the spouses' striving for family life cohesion, which agrees with the present study findings.

The experience of Iranian men in this study indicates that life has a vague future, so that wives are always worried about the outcome of treatment and the consequences of their illness. Despite all the efforts spouses make for survival of the patient, the ambiguous future about the disease casts a shadow over all their lives. Many studies have referred to this issue as a reality associated with patients (Gao et al., 2019; Ghaemi et al., 2019; Younes Barani et al., 2019).

Spouses are also faced with a sense of losing their self-concept. Spouses of women with breast cancer have had to discard everything relating to themselves due to performing various tasks and accepting new roles imposed on them by the disease. Many of their recreational activities, friendly relations and many other activities are significantly reduced or eliminated, and they suffer several physical and mental problems due to these additional pressures. In this respect, Girgis et al. (2013) refer to the role and the influence of cancer on caregivers in the form of physical, mental, and social disorders, and its effect on relationships, as well as the financial burden. Given the ruling religious-national culture in Iran, and the supportive role expected of spouses in the family, spouses' coping with their wives' disease should be addressed. Such intervention can be a strategy for solving the problem of patients with cancer in order to improve patient care conditions, help coping with the disease, and create a peaceful family atmosphere.

\section{Limitations}

The present study limitations included limited generalizability of data, which occurs in interpretive hermeneutic phenomenological studies due to profound data relating to the lived experiences. To overcome this limitation, experiences of participants from two regions in Iran were used. However, the present study results can only be applied in Iran because the concept of coping in spouses of women with breast cancer can be different in other countries. Furthermore, due to the traditional context of the population and the likelihood of complying with certain Islamic rules and the gender of the interviewer, participants may have been unable to comfortably talk about certain issues. The researcher made all efforts to assure participants and investigate the phenomenon of coping deeply.

One of the strengths of this study is the method and approach used as it considered the experience of the participants as they lived it. Emphasis on attention and assistance to the spouses of women with breast cancer in coping with their wives' illness can be used by institutions and treatment staff. It is also recommended that further studies be performed to 
assess the coping of the spouses of women with breast cancer. It is also recommended that further studies be performed to generate coping measuring instruments in the male spouses of women with breast cancer for use in Iran.

\section{CONCLUSION}

The results of this study exploring the lived experience of the male spouses of women with breast cancer indicate that they have many problems coping with the situation. Coping in spouses of women with breast cancer is described in five themes: emotional pain, shouldering the burden of care, striving for family life cohesion, future in ambiguity, and a sense

\section{REFERENCES}

Abachizadeh, K., Moradi-Kouchi, A., Ghanbari-Motlagh, A., Kousha, A., Shekarriz-Foumani, R., \& Erfani, A. (2018). Breast cancer in Iran: Levels, variations and correlates. Community Health (Salāmat-i ijtimā̄̄), 5(1), 11-21.

Braun, M., Mikulincer, M., Rydall, A., Walsh, A., \& Rodin, G. (2007). Hidden morbidity in cancer: spouse caregivers. Journal of Clinical Oncology, 25(30), 4829-4834.

Bray, F., Ferlay, J., Soerjomataram, I., Siegel, R. L., Torre, L. A., \& Jemal, A. (2018). Global cancer statistics 2018: GLOBOCAN estimates of incidence and mortality worldwide for 36 cancers in 185 countries. CA: a cancer journal for clinicians, 68(6), 394-424.

Burkoski, V., Yoon, J., Hutchinson, D., Solomon, S., \& Collins, B. E. (2019). Experiences of Nurses Working in a Fully Digital Hospital: A Phenomenological Study. Canadian Journal of Nursing Leadership, 32(Sp), 72-85.

Cebeci, F., Yangin, H. B., \& Tekeli, A. (2012). Life experiences of women with breast cancer in south western Turkey: A qualitative study. European Journal of Oncology Nursing, 16(4), 406-412.

Charvoz, L., Favez, N., Notari, S. C., Panes-Ruedin, B., \& Delaloye, J.-F. (2016). A survey of couples facing breast cancer in women. In C. R. In M. Oris, D. Joye, \& M. E. Stähli (Ed.), Surveying human vulnerabilities across the life course (Vol. 3, pp. 113-129): Springer, Cham.

Çömez, S., \& Karayurt, Ö. (20I6). We as spouses have experienced a real disaster!: A qualitative study of women with breast cancer and their spouses. Cancer nursing, 39(5), E19-E28.

Dorval, M., Guay, S., Mondor, M., Masse, B., Falardeau, M., Robidoux, A., . . Maunsell, E. (2005). Couples who get closer after breast cancer: frequency and predictors in a prospective investigation. Journal of Clinical Oncology, 23(15), 3588-3596.

Duprez, C., Vanlemmens, L., Untas, A., Antoine, P., Lesur, A., Loustalot, C., ... Carlier, D. (2017). Emotional distress and subjective impact of the disease in young women with breast cancer and their spouses. Future Oncology, 13(29), 2667-2680.

Ferlay, J., Steliarova-Foucher, E., Lortet-Tieulent, J., Rosso, S., Coebergh, J.-W. W., Comber, H., ... Bray, F. (2013). Cancer incidence and mortality patterns in Europe: estimates for 40 countries in 2012. European journal of cancer, 49(6), 1374-1403.

Fink, G. (2016). Stress: Concepts, cognition, emotion, and behavior: Handbook of stress series (Vol. 1): Academic Press.

Folkman, S., \& Lazarus, R. S. (1988). Manual for the ways of coping questionnaire. Palo Alto: CA: Consulting Psychologists Press.

Gao, L., Liu, J. E., Zhou, X. P., Su, Y. L., \& Wang, P. L. (2019). Supporting her as the situation changes: A qualitative study of spousal support strategies for patients with breast cancer in China. European journal of cancer care, 29(1), e13176. of losing self-concept. Since coping in spouses of Iranian women with breast cancer is a multidimensional problem and can be different in other countries due to differences in cultural aspects and in health care systems, spouses of women with breast cancer can be steered onto the path of coping by understanding the concept of coping in them and addressing this issue through health strategies. In turn, measures can be taken toward effective medical care for the patients and their spouses. Careful planning is also advised to pay attention to the spouses of cancer patients and their adaptation to the situation and to provide the conditions for better facilitation of adaptation to this issue.

Ghaemi, S. Z., Keshavarz, Z., Tahmasebi, S., Akrami, M., \& Heydari, S. T. (2019). Conflicts women with breast cancer face with: A qualitative study. Journal of family medicine and primary care, 8(1), 27.

Ghaffari, F., Shali, M., Shoghi, M., \& Joolaee, S. (2014). Psychometric properties of the persian version of the self-assessed support needs questionnaire for breast cancer cases. APJCP, 15(3), 1435-1440.

Girgis, A., Lambert, S., Johnson, C., Waller, A., \& Currow, D. (2013). Physical, psychosocial, relationship, and economic burden of caring for people with cancer: a review. Journal of Oncology Practice, 9(4), 197-202.

Glajchen, M. (2004). The emerging role and needs of family caregivers in cancer care. The journal of supportive oncology, 2(2), 145-155.

Grunfeld, E., Coyle, D., Whelan, T., Clinch, J., Reyno, L., Earle, C. C., ... Janz, T. (2004). Family caregiver burden: results of a longitudinal study of breast cancer patients and their principal caregivers. Cmaj, 170(12), 1795-1801.

Hasson-Ohayon, I., Goldzweig, G., Braun, M., \& Galinsky, D. (2010). Women with advanced breast cancer and their spouses: diversity of support and psychological distress. Psycho-oncology, 19(11), 1195-1204.

Kershaw, T., Northouse, L., Kritpracha, C., Schafenacker, A., \& Mood, D. (2004). Coping strategies and quality of life in women with advanced breast cancer and their family caregivers. Psychology Q Health, 19(2), 139-155. doi: 10.1080/08870440310001652687

Lopes, V. B., Lobo, A. P. A., Da Silva Junior, G. B., Melo, A. K., Lamboglia, C. G., \& Silva, C. A. B. d. (2018). The experience of male spouses in the context of breast cancer: a systematic review of the literature. Psychology, health a medicine, 23(1), 89-98.

Mehrabi, E., Hajian, S., Simbar, M., \& Hoshyari, M. (2016). Religion, spirituality and coping with breast cancer: A phenomenological study. Journal of Research on Religion Q Health, 2(2), 12-23.

Momenimovahed, Z., \& Salehiniya, H. (2019). Epidemiological characteristics of and risk factors for breast cancer in the world. Breast Cancer: Targets and Therapy, 11, 151-164.

Montazeri, A., Vahdaninia, M., Harirchi, I., Harirchi, A. M., Sajadian, A., Khaleghi, F., . . . Jarvandi, S. (2008). Breast cancer in Iran: need for greater women awareness of warning signs and effective screening methods. Asia Pacific family medicine, 7(1), 6.

Nafissi, N., Khayamzadeh, M., Zeinali, Z., Pazooki, D., Hosseini, M., \& Akbari, M. E. (2018). Epidemiology and histopathology of breast cancer in Iran versus other Middle Eastern countries. Middle East Journal of Cancer, 9(3), 243-251.

Nasiri, A., Taleghani, F., \& Irajpour, A. (2016). Adjustment process in I ranian men to their wives' breast cancer. European journal of cancer care, 25(2), 307-317. 
Neris, R. R., \& Anjos, A. C. Y. d. (2014). Experience of spouses of women with breast cancer: an integrative literature review. Revista da Escola de Enfermagem da USP, 48(5), 922-931.

Northouse, L. L., Mood, D., Templin, T., Mellon, S., \& George, T. (2000). Couples' patterns of adjustment to colon cancer. Social science Q medicine, 50(2), 271-284.

Paley, J. (2018). Meaning, lived experience, empathy and boredom: Max van Manen on phenomenology and Heidegger. Nursing Philosophy, 19(3), e12211.

Sajadian, A., Heydari, L., \& Mokhtari, P. (2015). Investigating Care Problems in Family Care Care Patients with Breast Cancer. Iranian Journal of Breast Disease Research, 8(2), 7-14.

Smith, J. A. (2003). Qualitative psychology: A practical guide to research methods: Sage Publications, Inc.

Soothill, K., Morris, S., Thomas, C., Harman, J., Francis, B., \& McIllmurray, M. (2003). The universal, situational, and personal needs of cancer patients and their main carers. European Journal of Oncology Nursing, 7(1), 5-13.

Valle, R. S., King, M., \& Halling, S. (1989). An introduction to existential-phenomenological thought in psychology. In I. R. S. Valle \& S. Halling (Eds.), Existential-phenomenological perspectives in psychology (pp. 3-16): Springer.

van Manen, M. (2016). Researching lived experience: Human science for an action sensitive pedagogy: Routledge.

Walker, W. (2007). Ethical considerations in phenomenological research. Nurse researcher, 14(3), 36-45.

Weitzner, M. A., Jacobsen, P., Wagner, H., Friedland, J., \& Cox, C. (1999). The Caregiver Quality of Life Index-Cancer (CQOLC) scale: development and validation of an instrument to measure quality of life of the family caregiver of patients with cancer. Quality of life Research, 8(1-2), 55-63.

Xiong, M., Stone, T. E., Turale, S., \& Petrini, M. A. (2016). Women's experiences of making healthcare decisions about their breast cancer: A phenomenological study. Nursing \& health sciences, 18(3), 314-320.

Yeung, N. C., Zhang, Y., Ji, L., Lu, G., \& Lu, Q. (2018). Guilt among husband caregivers of Chinese women with breast cancer: The roles of male gender-role norm, caregiving burden and coping processes. European journal of cancer care, 27(5), e12872.

Younes Barani, Z., Rahnama, M., Naderifar, M., Badakhsh, M., \& Noorisanchooli, H. (2019). Experiences of Spouses of Women with Breast Cancer: A Content Analysis. Asian Pacific Journal of Cancer Prevention, 20(10), 3167-3172.

Yusoff, N., Reiko Yap, K., \& Ahmad, A. (2012). Husbands' experience with their wives' breast cancer: a qualitative study. Malaysian Journal of Public Health Medicine, 12(1), 31-38.

Zahlis, E. H., \& Lewis, F. M. (2010). Coming to grips with breast cancer: the spouse's experience with his wife's first six months. Journal of psychosocial oncology, 28(1), 79-97.

Zere, E., Mandlhate, C., Mbeeli, T., Shangula, K., Mutirua, K., \& Kapenambili, W. (2007). Equity in health care in Namibia: developing a needs-based resource allocation formula using principal components analysis. International Journal for Equity in Health, 6(1), 3.

Zimmermann, T. (2015). Intimate relationships affected by breast cancer: interventions for couples. Breast Care, 10(2), 102-108. 